\title{
Mentiras Sãs: Sobre Dois Filmes de Apropriação 'Falsos'
}

\author{
TIAGO BAPTISTA \\ Instituto de História Contemporânea \\ Universidade Nova de Lisboa
}

\begin{abstract}
A glória de fazer cinema em Portugal (Manuel Mozos, 2015) and Redemption (Miguel Gomes, 2013) are recent examples of "appropriation films," a filmmaking practice that has seen important development in Portugal over the past fifteen years. The two films stand out, however, because they use fabricated archival footage (Mozos) and real archival footage (Gomes) to tell a fictional story. This places them within the scope of the "fake documentary" genre. If one accepts current scholarly definitions of appropriation films, it is possible to see these two "fake" films as apt illustrations of the epistemological and pedagogical potential of the appropriation film with respect not only to cinema but also to historical knowledge.
\end{abstract}

Keywords: Appropriation film; Portuguese cinema; fake documentary; Miguel Gomes; Manuel Mozos

Nos últimos dez anos, vários filmes portugueses destacaram-se pelo emprego parcial ou total de imagens de arquivo, isto é, originalmente produzidas noutro contexto histórico e com outra função e hoje apenas disponíveis em arquivos audiovisuais (de cinema e televisão, ou online). É o caso, entre outros, dos filmes Kuха Kanema: o nascimento do cinema (Margarida Cardoso, 2003), Natureza morta (Susana de Sousa Dias, 2005), Fantasia lusitana (João Canijo, 2010), ou Linha vermelha (José Filipe Costa, 2011). Estes filmes têm ainda em comum o facto de mobilizarem imagens de arquivo para analisar períodos históricos centrais do século XX português, como a ditadura (1926-1974) ou a Revolução de 1974 (Baptista). 
Estas obras transformam o contexto de uso e o significado das imagens de arquivo, reconfigurando as relações entre imagem e som, para sugerir uma interpretação alternativa do passado. São aquilo a que vários autores têm chamado, na esteira do trabalho de Jaimie Baron, "filmes de apropriação" (911). Nestas obras, a mobilização de imagens de arquivo nunca é dissociada do emprego de estratégias formais que, por um lado, sublinham a sua dimensão material, e por outro, chamam a atenção para os processos semióticos que lhes dão sentido. Os filmes de apropriação possuem, pois, a capacidade de proporcionar ao espectador uma experiência em segunda mão do passado, em que se torna claro o carácter construído não só da imagem cinematográfica, mas também do próprio conhecimento histórico tal como é mediado pelo cinema. Deste modo, torna-se possível perceber melhor o paralelo estabelecido por Baron entre a desconstrução da imagem cinematográfica preconizada pelos filmes de apropriação e a desnaturalização das narrativas historiográficas defendida pelo Novo Historicismo e por autores como Hayden White através do seu conhecido conceito de meta-história. Trazendo as conclusões deste autor para o terreno do filme de apropriação, pode dizer-se que o que estas obras fazem não é tanto reconfigurar as narrativas audiovisuais para construir uma versão alternativa do passado, mas sim sublinhar que só podemos aceder a esse mesmo passado através das interpretações que dele construímos.

Entre os fatores que ajudam a perceber a multiplicação de filmes de apropriação durante a última década destaca-se o trabalho dos arquivos audiovisuais e a disponibilidade de ferramentas digitais de visionamento, montagem e circulação de imagens em movimento. O trabalho dos arquivos audiovisuais traduziu-se em processos de prospeção e conservação que aumentaram consideravelmente o número de obras acessíveis pelo público. Estes processos produziram efeitos sobretudo após a abertura, em 1996, do Arquivo Nacional das Imagens em Movimento (ANIM, o centro de conservação da Cinemateca Portuguesa-Museu do Cinema), e a recuperação do arquivo histórico da televisão pública portuguesa (a RTP), em meados de 2000. Tal como sucedeu noutros países, verificou-se uma influência recíproca entre a disponibilização de mais imagens e o aumento da pressão pública para dilatar ainda mais a sua quantidade, bem como para melhorar as suas condições de visionamento e reutilização. Não obstante as limitações na capacidade de resposta dos arquivos e as barreiras impostas ao livre acesso e reutilização 
dessas imagens por questões de conservação e direitos de autor, os últimos vinte anos ficaram marcados pelo desenvolvimento de um verdadeiro "mercado do património" cinematográfico (Costa) que não parou de proporcionar novas utilizações, em diferentes contextos, para o património audiovisual português.

Por outro lado, os equipamentos e ferramentas de visionamento e montagem digital estimularam ainda mais a reutilização desta massa cada vez maior de imagens de arquivo, tornando consideravelmente mais fácil ver, montar, distribuir e exibir imagens cinematográficas. Da pesquisa à projeção, todas as etapas do trabalho sobre imagens de arquivo foram agilizadas pelo uso de tecnologias digitais que facilitam a visualização, cópia, apropriação, partilha e recirculação de mais imagens em menos tempo junto de muitos mais espectadores. No entanto, o recurso a sistemas de edição não-linear trouxe ainda outro tipo de benefícios como o reforço do caráter gestual da montagem (Grant). Com efeito, a montagem digital acarreta uma relação muito próxima com as imagens que assenta na manipulação intensiva dos seus parâmetros formais: alteração da velocidade e da direção da reprodução, dos valores de cor e contraste, ou até mesmo do enquadramento. A montagem digital permite, assim, uma forma de conhecimento que, por um lado, cria sentidos a partir da manipulação das próprias imagens, ao invés de lhes impor um argumento previamente definido, e por outro lado, liga a investigação sobre cada filme a uma revelação sobre diversos princípios formais do cinema. Finalmente, as deslocações e justaposições de sons e imagens ancoradas pela montagem digital expõem também a dimensão material de qualquer filme, abrindo vias de reflexão sobre a natureza e o trajeto histórico dos elementos que o constituem (da rodagem ao arquivo, do negativo à cópia preservada) e, ainda, sobre os mecanismos fundamentais de produção de sentido no cinema.

Dois filmes recentes empurram até ao limite as questões levantadas pelo filme de apropriação: refiro-me às curtas-metragens Redemption (Miguel Gomes, 2013) e A glória de fazer cinema em Portugal (Manuel Mozos, 2015). Redemption combina filmes domésticos (ou de família), documentários e trechos de um filme de ficção com a leitura de quatro cartas pessoais (outro documento de arquivo arquetípico). No final do filme, as cartas são atribuídas a quatro líderes europeus (Pedro Passos Coelho, Silvio Berlusconi, Nicolas Sarkozy e Angela Merkel), revelando o truque: além das disparidades mais ou menos óbvias e adivinháveis entre locução e imagens, existe uma outra 
disparidade, insanável, entre os filmes e aquelas quatro figuras públicas (aqueles filmes de família não documentam, manifestamente, a biografia dos quatro líderes europeus). Uma legenda final esclarece que acabámos de ver uma obra de ficção. A glória de fazer cinema em Portugal, por seu lado, conta a história de um filme que nunca existiu, escrito por José Régio e rodado em Vila do Conde em 1930. Manuel Mozos combina a sua narração dos falsos acontecimentos históricos com várias fotografias e documentos de arquivo autênticos, mas também com 4 minutos de imagens fabricadas do alegado filme. O engano também é revelado apenas no genérico final em que se inclui uma legenda que, à semelhança da de Redemption, informa o espectador que este acabou de assistir a uma obra de ficção.

Estes filmes representam, assim, duas reescritas radicais da história do cinema português e da história europeia recente. Por outras palavras, os filmes de Mozos e Miguel Gomes apropriam imagens públicas e privadas para construir uma versão alternativa da história. No entanto, ao mobilizar imagens de arquivo para contar uma história que confessadamente não ocorreu, estes filmes entram no terreno do "fake documentary," género que usa imagens de arquivo autênticas (ou mesmo fabricadas) como ponto de partida de um discurso ficcional, assumindo essa ficcionalização em diferentes graus. Como vários autores já notaram, a ideia de "falso" é sempre problemática. No campo da história da arte, as falsificações são consideradas por vezes mais reveladoras sobre determinada época histórica do que as obras autênticas do mesmo período. Por outro lado, as falsificações também desafiam os limites da prática artística e as convenções dos processos de legitimação social e cultural da arte (Keats; Sá). No campo do cinema, o género do "fake documentary" desempenha um papel semelhante, problematizando o conceito de "falso" e demonstrando como tal conceito apenas contribui para reforçar a crença no estatuto de "verdade" do documentário-como se este não assentasse igualmente em estratégias retóricas de reorganização e de resignificação da realidade filmada, ou da imagem de arquivo (Baron; Lebow).

O que estes dois filmes de apropriação demonstram, pelo contrário, é que o trabalho sobre imagens de arquivo é sempre "falso" no sentido em que assenta sobre a demonstração do carácter construído de todo o discurso cinematográfico. Podem, por isso, ser descritos, como fez Gomes a propósito de Redemption, como "mentiras sãs" cujo objetivo é usar estratégias ficcionais 
para desafiar os discursos predominantes não só sobre o cinema contemporâneo (e em particular, sobre o que é um "documentário" ou um "filme de apropriação"), mas também a história recente de Portugal e da Europa (Gester). Deste modo, o propósito político do filme de apropriação "falso" torna-se mais evidente. Através de estratégias de falsificação, estes filmes questionam o estatuto de "verdade" atribuído a alguns discursos (e não a outros) e a legitimidade de quem determina esse estatuto, contribuindo assim, como veremos, para libertar o presente de interpretações instrumentalizadas do passado.

\section{Sabotar a história}

Encomenda do Festival Internacional de Cinema de Vila do Conde, A glória adota a postura de um documentário histórico sobre um filme de José Régio alegadamente encontrado por um colecionador local entre um lote de velhas bobinas de película. O título é uma citação da carta, autêntica, endereçada por Régio ao seu amigo Alberto de Serpa convidando-o a participar num projeto que lhes traria "a glória de fazer cinema em Portugal." A carta, que aborda a questão prática de obter uma câmara para iniciar a rodagem, empresta verosimilhança à premissa do filme de Mozos. O mesmo se pode dizer das conhecidas ligações ao cinema de Régio, quer através das críticas que publicou na revista Presença, quer das suas obras adaptadas ao cinema por Manoel de Oliveira. Estreado em Vila do Conde, cidade natal de Régio, poucos meses após a morte de Oliveira, A glória é uma homenagem à amizade que uniu os dois homens e, ainda, uma maneira de associar o local onde decorre o festival que encomendou o filme de Mozos a figuras (reais) e a momentos fundadores (inventados) da história do cinema português.

$\mathrm{O}$ próprio nome do realizador também contribui para o efeito de verosimilhança de A glória. Mozos, que trabalha como técnico de conservação no arquivo fílmico da Cinemateca, realizou vários documentários sobre a história do cinema português. O seu conhecimento e o seu gosto pela revisitação de autores e períodos exteriores aos cânones da crítica e da história do cinema (os realizadores portugueses da década de 1950, por exemplo) são conhecidos e estão documentados em várias entrevistas e outras declarações. Nada mais natural, portanto, do que a encomenda a Mozos, pelo festival de Vila 
do Conde, desta escavação arqueológica sobre o projeto cinematográfico de Régio. No entanto, a mesma biografia profissional de Mozos também deveria instalar imediatamente uma dúvida na mente do espectador. Tendo Mozos sido protagonista de uma das mais atribuladas histórias de produção do cinema português (com o filme Xavier, cuja rodagem se interrompeu durante uma década), não seria o título "a glória do cinema português" uma referência irónica, se não mesmo sarcástica, às enormes dificuldades de fazer cinema em Portugal?

A dúvida é parte integrante de A glória e faz deste filme um divertimento, como explicou Mozos, mas não à custa do espectador. Pelo contrário, Mozos, tal como Gomes, acumula no seu filme várias pistas que vão assinalando a possibilidade de estarmos perante um documentário "falso." Trata-se, como admitiu Mozos, de uma estratégia deliberada de produzir no espectador uma impressão de ambiguidade e incerteza em relação ao que se está a ver, o que aproxima esta prática cinematográfica dos fundamentos do cinema moderno e do emprego de estratégias reflexivas para desestabilizar a experiência de receção (Mourinha).

Esta desestabilização assenta, desde logo, nas várias inconsistências históricas óbvias que pontuam o filme. Primeiro, temos o facto de as presumíveis imagens do filme perdido serem projetadas no pequeno auditório do Teatro Municipal de Vila do Conde, o que não só indicia uma relação fundadora das mesmas com o Festival que encomendou o filme de Mozos e ali tem o seu quartel-geral, mas também constituiria uma prova da projeção (ilegal e potencialmente catastrófica) de um filme em suporte de nitrato naquele mesmo auditório. Em segundo lugar, temos as várias referências ao facto de o filme de Régio inaugurar o cinema português. Ora, naquele período, não só este cinema contava já com um longo historial de produções cinematográficas, como acabara, naquele mesmo ano de 1930, de estrear Maria do Mar (Leitão de Barros), frequentemente considerado uma das obras-primas do cinema mudo português, igualmente passado em ambiente marítimo e, mais importante, também caraterizado por deslizar entre o terreno da ficção e do documentário. Em terceiro lugar, apesar de o presumível realizador do filme ser uma personagem histórica (R. Caillaud foi de facto assistente de realização de René Clair em Entr'Acte, 1924), já o seu mentor, Jonathan Fakenham, é uma personagem de ficção com uma biografia inventada (apesar de objeto de um 
artigo "falso" de Eduardo de Brito publicado em 2012), sendo o seu nome reconhecido imediatamente por alguns cinéfilos como o de uma personagem de Barry Lyndon (1975), de Stanley Kubrick.

Mozos combina estes factos falsos com eventos e personagens verdadeiros, ou astutamente verosímeis. Por exemplo, todos os outros filmes encontrados com as imagens de Régio são reais; a carta de Régio abundantemente citada é real (e ocupa, aliás, lugar de destaque no museu da cidade); R. Caillaud existiu e trabalhou com René Clair, que foi uma referência importante para os cinéfilos e realizadores portugueses do final dos anos de 1920; a batalha da Primeira Guerra Mundial onde Caillaud combateu teve lugar; tal como a sessão de Fátima milagrosa (Rino Lupo, 1928) em Vila do Conde a que Caillaud e Régio teriam assistido juntos; os vários locais mostrados no filme existem mesmo; e Régio e Oliveira, como é sabido, mantiveram de facto uma duradoura amizade que ficou marcada por várias expressões públicas de admiração recíproca.

Se em A glória existem, pois, pelo menos tantas razões para acreditar como para desconfiar, existe um mecanismo, porém, que faz pender a balança para o lado da construção. Em pelo menos duas cenas, o corte entre um plano filmado no presente e as imagens encontradas é antecedido pelo efeito de degradação da película cinematográfica. $\mathrm{O}$ artifício é como que acionado demasiado cedo, instalando a dúvida sobre o estatuto das imagens de Régio e Caillaud. A repetição deste efeito várias vezes ao longo do filme permite confirmar esta suposição, que se vê apoiada na constatação da cristalina definição da imagem a preto e branco por baixo das imperfeições (que apenas uma câmara e objetivas modernas podiam conseguir). As imperfeições surgem, assim, como um efeito acrescentado para simular a passagem do tempo, mas cujo modo de aplicação aponta para a sua contemporaneidade, sugerindo assim que Mozos quer tanto enganar o espectador como dar-lhe a oportunidade de se aperceber do logro.

Com a autoridade do seu tom sóbrio e pedagógico, a narração, lida pelo próprio Mozos, une o falso, o autêntico e o verosímil numa versão coerente da história que viria preencher uma lacuna no conhecimento do espectador que ele nem sequer supunha existir. Ou seja, o filme cria a sua própria necessidade ao suscitar a dúvida que se encarrega de esclarecer. A glória fala, portanto, do desejo de verdade e de história que as imagens de arquivo parecem prometer sempre, mas apenas para mostrar como é fácil trair este desejo e mostrá-lo pelo que ele é: uma forma de "epistemofilia," isto é, não o desejo de acumular mais 


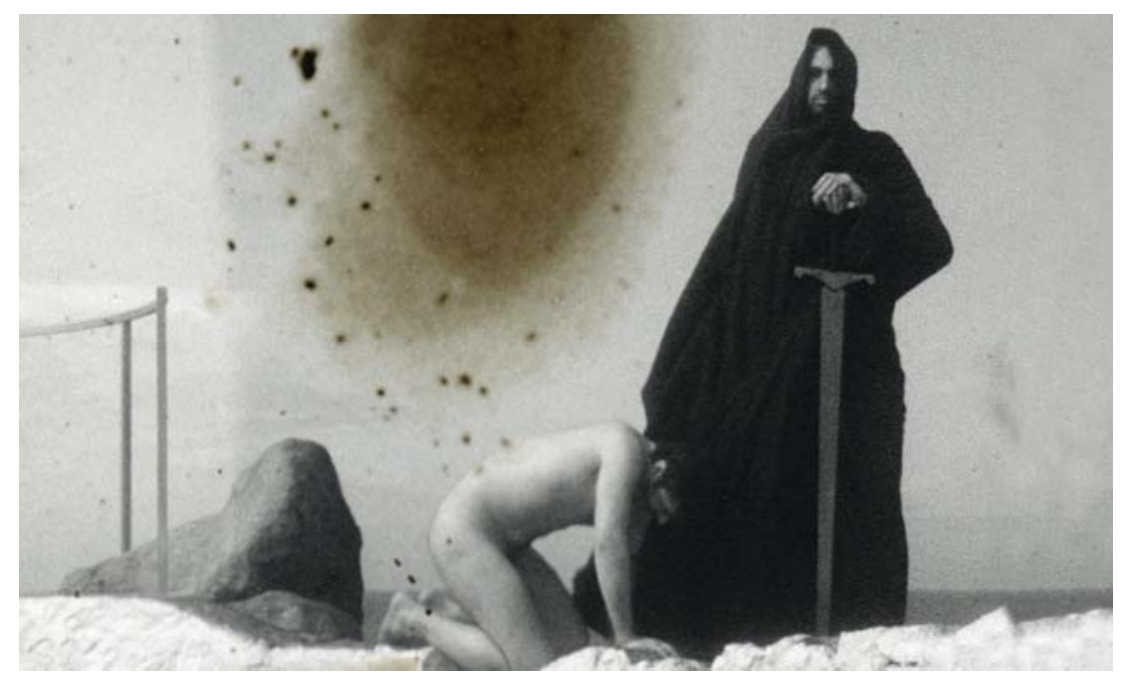

conhecimento sobre o mundo, mas sim o desejo da ilusão de poder sobre o mundo que tal conhecimento acarreta (Lebow 227). Ao falsificar o filme de Régio, Mozos questiona a predisposição do espectador para aceitar não só a autenticidade das representações do passado construídas pelo cinema a partir de imagens de arquivo, mas também para aceitar a autoridade de quem constrói esses mesmos discursos.

\section{Austeridade sem redenção}

Realizado entre Tabu (2012) e o arranque do projeto que daria origem ao tríptico As mil e uma noites (2015), Redemption articula elegantemente a passagem de um filme a outro. Num momento em que não tinha a certeza de poder vir a filmar em Moçambique, Gomes explorou a hipótese de evocar os espaços coloniais de Tabu através de imagens de filmes de família de pequeno formato (Câmara). Esta peripécia de produção revelaria um novo universo de imagens mobilizáveis para o trabalho do realizador — os arquivos familiares de Redemption - mas também o potencial destas imagens para prolongar a evocação simultânea de memórias pessoais e coletivas que já estruturara Tabu. Redemption herdaria ainda de Tabu a importância de uma voz off na primeira pessoa que organiza no presente memórias ou imagens do passado, emprestando-lhes desse modo coerência narrativa, mas sabotando também a sua 
verosimilhança de tempos a tempos, como o provam os vários anacronismos ou atropelos da história do colonialismo português que pontuam, mais ou menos discretamente, a secção "Paraíso" de Tabu.

O trabalho sobre estes arquivos familiares foi concretizado durante a estadia de Gomes como professor convidado no Le Fresnoy-Studio National des Arts Contemporains onde, segundo a tradição desta escola, o docente acompanha os alunos durante a fase de realização dos seus projetos ao mesmo tempo que aceita fazer um filme de encomenda. Regressarei à importância de Redemption ter sido realizado num contexto escolar, mas limito-me, por agora, a imputar ao ambiente internacional da escola o alargamento da investigação sobre os filmes de família portugueses a um arquivo de filmes de família europeus e da reflexão sobre o colonialismo português à história e à identidade da Europa. Ao estender o seu interesse a estes temas, Gomes prefigurava o projeto d'As mil e uma noites, que arrancou pouco depois de Redemption ter estreado no Festival de Cinema de Veneza, em agosto de 2015. Para construir o argumento de As mil e uma noites, Gomes trabalhou sobre histórias reais recolhidas por uma equipa de jornalistas profissionais, que durante mais de um ano selecionaram retratos de um país vivendo os efeitos de uma crise socioeconómica profunda, causada pela imposição das medidas de austeridade financeira pela chamada troika de instituições internacionais (Comissão Europeia, Banco Central Europeu e Fundo Monetário Internacional) como contrapartida do resgate financeiro a que o pais foi sujeito. Antecipando este filme, Redemption opera já no mesmo registo que "delira e inventa a partir de possibilidades do mundo real," misturando o real e a ficção, o pessoal e o coletivo, o nacional e o europeu, com o objetivo confesso de questionar os discursos públicos predominantes sobre a bondade e a inevitabilidade da austeridade e, consequentemente, do projeto europeu que a impôs (Câmara).

É possível ver aqui, como alguns críticos fizeram, a persistência de temas prediletos do autor, tais como a empatia por personagens desligados do seu passado, a utilização do cinema como substituto da memória, a criação de zonas cinzentas entre a memória pessoal e a coletiva (nacional), ou o vai e vem entre a sátira e a simpatia pelos eventos e pessoas filmados (Nelson). Aquilo que une estes temas é o emprego da ficção como forma de pensar a realidade e a utilização ostensiva de técnicas cinematográficas que recordam ao espectador o papel do cinema na construção destas versões da realidade: isto é, que trazem 
para o ato de receção a consciência do papel mediador do cinema na representação do mundo pró-fílmico. Estas estratégias reflexivas ganham um sentido de urgência em Redemption e mais ainda em As mil e uma noites, nos quais falar sobre o estado do país se torna impossível sem falar também do estado do cinema. As ameaças ao financiamento do cinema português (que abrem o mais recente filme de Gomes) são representadas como uma ameaça à possibilidade de manter um discurso crítico sobre o país que concorresse com as narrativas dominantes veiculadas pela comunicação social, pelo discurso político e pelo senso comum. Nestes filmes, o sentido de urgência justifica levar mais longe a intromissão entre realidade e ficção, dobrando a operação estética com um imperativo ético que exige que o cinema reaja rapidamente à realidade, oferecendo não apenas um comentário sobre ela, mas também propostas para refletir criticamente sobre as próprias condições de possibilidade dessa realidade - isto é, sobre os alicerces do discurso ideológico dominante. A falsificação da realidade patente em Redemption deve ser entendida, assim, no contexto deste imperativo ético que se revela como uma batalha pela interpretação da realidade (e da história) em que o cinema quer participar, ombro a ombro com a comunicação social e o discurso político, funcionando não tanto como um contraponto ou a instância criadora de mais uma versão alternativa da realidade, mas sim como uma ferramenta de literacia epistemológica capaz de oferecer instrumentos para entender (e desconstruir) as condições de possibilidade de todas as representações da realidade (cinematográficas, historiográficas, ou políticas).

Percebe-se melhor, a esta luz, os termos em que Gomes defendeu os méritos da falsificação da realidade operada por Redemption: "A ficção é uma mentira sã. A mentira assumida não é um engano. Creio que é preciso usar as boas mentiras contra as más mentiras - as mentiras, ponto-que hoje saem das bocas de muitas pessoas com responsabilidades públicas" (Gester). O motivo da mentira ou, melhor, da dicotomia falso/verdadeiro atravessa, aliás, toda a curta-metragem de Gomes. No episódio francês, o tema é evocado de maneira relativamente direta através dos raccords que estabelecem uma continuidade, enganadora, entre um avião de brincar e um avião verdadeiro. O episódio italiano, por seu lado, inclui a célebre sequência final de $O$ milagre de Milão (Vittorio de Sica, 1951), na qual Totò e Lolotta voam pelos céus de Milão montados numa vassoura. O efeito de sobreimpressão que permite o "voo" 
evoca explicitamente a "mentira" cinematográfica, isto é, a capacidade de iludir o espectador. No entanto, a natureza evidente da trucagem torna a mentira transparente, pelo que a mesma sequência também pode ser vista como ilustrativa do imperativo estético e ético de Redemption: usar a mentira para dizer verdade, ou seja, para alertar o espectador para o caráter construído da imagem cinematográfica.

A mobilização formal deste imperativo traduziu-se numa estratégia de multiplicação das relações entre imagem e som, criando assim inconsistências e dissociações que levam ao extremo as disparidades típicas do filme de apropriação. Esta estratégia ocorre, desde logo, ao nível do comentário. Ao contrário do que acontece em A glória, a narração de Redemption não só é múltipla como abdica de impor um sentido unívoco às imagens. Narração e imagens discorrem como discursos paralelos. No episódio que abre o filme, a justaposição de documentários etnográficos portugueses (como Falamos de Rio de Onor, de António Campos, 1974, e Máscaras, de Noémia Delgado, 1976) com o documentário colonial Esplendor selvagem (António de Sousa, 1972) confunde deliberadamente o espectador através da montagem cruzada de imagens e sons de Portugal e de África. É difícil, aqui, identificar sempre com segurança se as associações entre imagem e som são geograficamente corretas ou, pelo contrário, correspondem a uma intromissão da memória do mundo rural português no espaço colonial, ou vice-versa. ${ }^{1}$ Já no episódio alemão, as inconsistências introduzidas por Gomes resultam da sobreimpressão de filmes científicos (com imagens térmicas, diagramas e fórmulas matemáticas) aos arquivos familiares que mostram várias festas de casamento. Neste caso, é um género cinematográfico (o filme científico) que se intromete ostensivamente noutro (o filme de família), produzindo um efeito reflexivo semelhante ao da trucagem de $O$ milagre de Milão.

A instabilidade semântica (Adelaar) de Redemption situa-se muito além de qualquer justificação narrativa que pretendesse relacionar dois espaços diferentes ou evocar a irrupção de memórias do passado narrado no tempo presente do ato de narração. As relações entre imagem e som multiplicam e complicam, mais do que fecham e esclarecem, as relações entre locais, pessoas e linhas temporais. Deste modo, Redemption obriga o espectador a uma leitura

\footnotetext{
${ }^{1}$ Para uma análise do episódio português de Redemption, ver Schefer.
} 


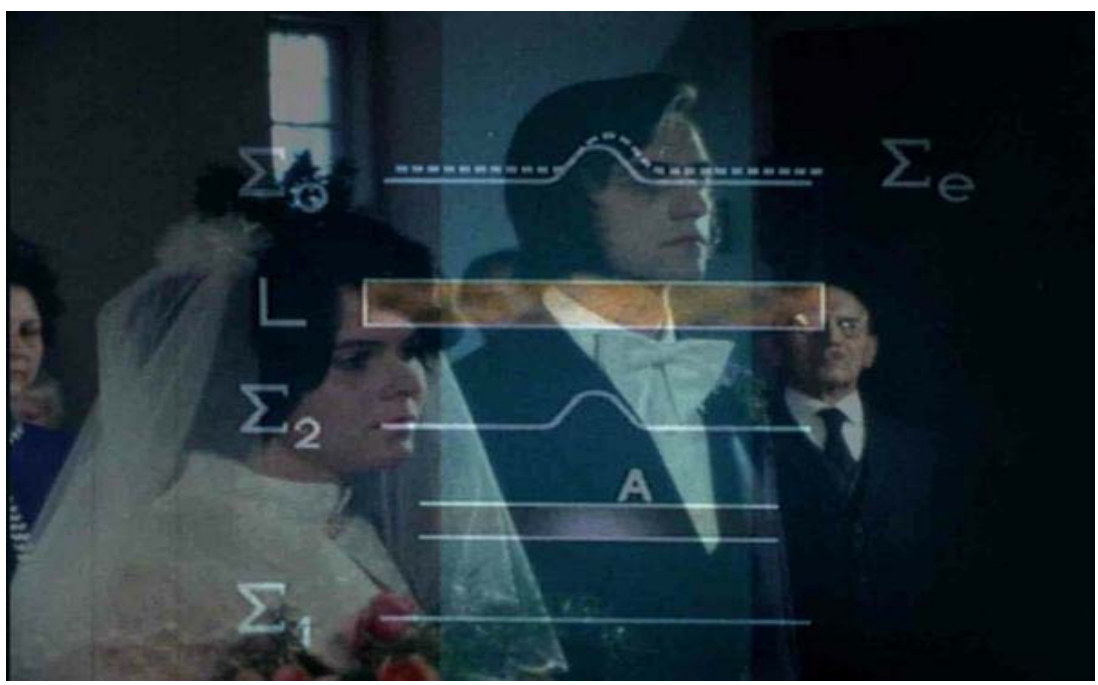

ativa marcada, primeiro, pela consciência das decisões autorais que levaram o realizador a escolher combinar estas imagens e sons e, depois, pela interrogação sobre a razão de ser dessas mesmas escolhas. A consequência desta estratégia é que imagens e narração acabam por se desmontar mutuamente: a etnografia do espaço rural português não mostra o país frio, feio e triste de que fala a primeira carta; os documentários italianos fascistas ignoram os afetos da segunda carta; os filmes de uma família feliz em férias junto ao mar negam o pai ausente da terceira carta; e a frugalidade das bodas filmadas na última carta parecem negar os prazeres (culpados) experimentados pela sua narradora.

A receção de Redemption é marcada, finalmente, pela contaminação cruzada permanente entre espaços e, sobretudo, tempos históricos diferentes: Portugal pós-1974 e África colonizada, o presente político dos narradores italiano e francês e os seus passados amorosos e familiares, e o remorso da narradora alemã que lamenta a memória de uma escapadela à Alemanha ocidental. A ambiguidade da montagem entre as diferentes imagens e sons resulta na contaminação recíproca de presente e passado, cujas relações causais são sistematicamente postas em cheque. Ao problematizar a relação entre presente e passado, Gomes questiona a possibilidade de arrependimento dos narradores. As imagens não suportam necessariamente a sua interpretação do passado, pelo que não podem contribuir para a sua redenção. Neste processo, é o próprio cinema, afinal, que encontra uma chance de redenção. 


\section{Mentiras sãs}

Como defendeu Baron, o filme de apropriação pode caracterizar-se não só pelo conteúdo e proveniência das imagens que mobiliza, mas sobretudo por uma experiência de receção particular, que a autora designou como o "efeito de arquivo": a consciência, da parte do espectador, de que está a ver imagens pertencentes a outro tempo histórico (16). A glória e Redemption estão organizados de uma forma que potencia o "efeito de arquivo" para canalizar os estados emocionais e intelectuais associados a esta forma de experiência do passado. $\mathrm{O}$ facto de assentarem em estratégias de falsificação fílmica apenas contribui para chamar a atenção para os processos de produção de sentido do texto audiovisual em geral, e deste género cinematográfico em particular, ao mesmo tempo que nos obrigam a questionar a utilidade da própria designação de filme de apropriação "falso." Afinal, não é o método e o objetivo do filme de apropriação dizer sempre "mentira" para, desse modo, questionar a autoridade do "verdadeiro" e de quem pode determiná-lo, seja no documentário, ou em qualquer outro contexto de resignificação das imagens de arquivo?

Resta avaliar o valor e as consequências políticas deste gesto. Não é irrelevante que os dois filmes tenham uma relação fundadora com um festival (A glória) e com uma escola de cinema (Redemption). Se Redemption resume uma pedagogia dos rudimentos dos processos de criação cinematográfica (o papel criador da montagem e da recombinação de imagens e sons), A glória sugere que nem os públicos especializados dos festivais de cinema estão livres de continuar a questionar o que sabem, ou julgam saber, sobre a história do cinema. A primeira parte da resposta sobre o valor político destes filmes prende-se com a tensão produtiva entre a perpetuação da cinefilia enquanto saber especializado e fechado e a pedagogia do cinema enquanto forma que se aprende e ensina. Dito de outro modo, o valor político de um filme de apropriação depende menos de ser falso ou verdadeiro do que do seu potencial pedagógico sobre os processos de construção e legitimação da imagem cinematográfica.

Pode objetar-se que esta pedagogia é facilmente feita refém da noção de total arbitrariedade do discurso cinematográfico e historiográfico. É certo que, em alguns casos extremos, o potencial de desconstrução e reescrita da história do filme de apropriação tem sido usado por revisionistas, desde os adeptos de 
teorias da conspiração (como, por exemplo, aqueles que questionam a veracidade das aterragens lunares) até aos negadores do Holocausto (Baron 62). Aqui, pelo contrário, a desestabilização dos sentidos das imagens de arquivo reutilizadas questiona os seus usos mais convencionais com o objetivo de desafiar a autoridade daqueles que estão em posição de poder estabelecer determinadas versões do passado em detrimento de outras, impondo assim a naturalização das suas interpretações tanto sobre o cinema como sobre a história. Uma segunda parte da resposta sobre o valor político do filme de apropriação terá, então, que avaliar o posicionamento destes filmes nas lutas pela memória que pretendem branquear ou omitir eventos históricos relevantes no presente para a identidade das sociedades contemporâneas.

Um bom exemplo do papel que o filme de apropriação desempenha nesta representação contemporânea do passado é a questão da nostalgia (Baron 128). Como se posicionam A glória e Redemption em relação ao passado? Lastimam a sua perda irreparável como momento imaculado antes da queda num presente degradado? Ou entendem-no como parte de um processo histórico destinado a um devir permanente e ao qual não é possível aceder de forma completa, como um todo completo e imóvel? Ajudará recordar que A glória estreou em Vila do Conde dois anos depois de aquele festival ter dedicado uma retrospetiva a Bill Morrison, conhecido pelos seus filmes de apropriação constituídos inteiramente pela refilmagem de películas deterioradas (Ribas 97-98). Além disso, é possível aproximar A glória do trabalho de Morrison. Por um lado, os efeitos de degradação fabricados por Mozos repetem uma palete de cores e formas muito semelhante às dos filmes de arquivo (deteriorados) selecionados por Morrison. Por outro lado, se Morrison parece neutralizar a história dos filmes por si usados (o seu conteúdo icónico e percurso material é reduzido à estetização da sua degradação físico-química-principal, se não o único, critério da sua seleção e apropriação) no que se poderia considerar uma nostalgia afetiva, mas fundamentalmente acrítica e ahistórica, já Mozos parece adotar uma nostalgia reflexiva, que constrói as suas próprias marcas de degradação e, desse modo, se inscreve numa continuidade histórica em curso. Em A glória, o passado não é um território fechado e completo, passível de ser reanimado, mas sim um campo que não existe independentemente da sua reinvenção e reinterpretação permanentes a partir do presente. 
Já Redemption, num primeiro olhar, parece construir uma nostalgia restauradora, reacionária, que instala no passado uma suposta pureza prépecado original que motivaria o desejo de redenção dos quatro líderes europeus. Ao fazê-lo, é certo que o filme desloca para o terreno do estereótipo e da biografia pessoal a sua tentativa de perceber o presente através do passado: o retornado ressentido que se torna executor dum programa de austeridade (Passos Coelho); o pequeno burguês tornado milionário debochado (Berlusconi); o pai ausente tornado político nepotista (Sarkozy); a ossi provinciana tornada líder do país mais rico da Europa (Merkel). O poder explicativo e o emprego destes clichés são muito duvidosos, tal como a redução da política à biografia pessoal. No entanto, é inegável que Gomes oblitera duplamente qualquer relação nostálgica com o passado. Não só o passado é retratado como um momento de tristeza e fonte de infelicidade (e não como um momento a que se deseja regressar), como a revelação final de que observámos uma obra de ficção mostra que aquele passado só existe como construção do presente. Reside aqui a principal consequência política de Redemption, pois não se trata apenas de questionar as imagens públicas dos líderes europeus que aplicaram programas de austeridade financeira nos seus países. Trata-se, isso sim, de denunciar todas as narrativas históricas que escondem os traços da sua própria fabricação e sugerem uma relação linear de causalidade entre passado e presente - como a narrativa da austeridade - para justificar a inevitabilidade de certos atos no presente enquanto consequência do que teria acontecido no passado. Recusando o engano que reitera versões politizadas da "verdade" e do passado para condicionar o presente, estes dois filmes de apropriação "falsos" empregam "mentiras sãs" que nos convidam a considerar (e porventura a abraçar?) as consequências de um entendimento da história, e do cinema, como ato de reescrita permanente.

\section{Obras Citadas}

Adelaar, Samuel. "Miguel Gomes' Redemption and the Multiple Lives of the Moving Image.” www.academia.edu/17584669. Acesso em 22 maio 2017. Baptista, Tiago. "Cinema/história: o cinema como historiador do século XX português." Revista Camões, no. 24, 2016, pp. 47-58. 
Baron, Jaimie. The Archive Effect: Found Footage and the Audiovisual Experience of History. Routledge, 2014.

Brito, Eduardo. "Jonathan Fakenham, a condição do lugar e as origens do princípio discópico." Intervalo, no. 5, 2012, www.eduardobrito.pt/ fakenham.html. Acesso em 22 maio 2017.

Câmara, Vasco. "Uma dimensão íntima, um trágico sopro europeu no novo filme de Miguel Gomes." Público, 28 agosto 2013.

Campos, António, realizador. Falamos de Rio de Onor. Fundação Calouste Gulbenkian, 1974.

Canijo, João, realizador. Fantasia lusitana. Periferia Filmes, 2010.

Cardoso, Margarida, realizador. Kuха Kanema: o nascimento do cinema. Arte France Cinéma, 2003.

Claire, René, realizador. Entr'acte. Les Ballets Suedois, 1924.

Costa, José Manuel. "Notas sobre a percepção do cinema como património cultural." Leituras: Revista da Biblioteca Nacional, no. 14-15, 2004, pp. 59-68.

Costa, José Filipe, realizador. Linha vermelha. José Filipe Costa, 2011.

Delgado, Noémia, realizador. Máscaras. Centro Português de Cinema, 1976.

De Sica, Vittorio, realizador. Miracolo a Milano. Produzioni De Sica, 1951.

Dias, Susana de Sousa, realizador. Natureza morta. Amip, 2005.

Gester, Julien. "Miguel Gomes: 'Dire quelque chose sur ce monstre bordélique que l'on nomme l'Europe."' Libération, 5 setembro 2013. next.liberation.fr/cinema/2013/09/05/miguel-gomes-dire-quelque-chosesur-ce-monstre-bordelique-que-1-on-nomme-1-europe_929682. Acesso em 22 maio 2017.

Gomes, Miguel, realizador. As mil e uma noites: volume 1, o inquieto. O Som e a Fúria, 2015.

-. Redemption. O Som e a Fúria, 2013.

—. Tabu. O Som e a Fúria, 2012.

Grant, Catherine. "The Shudder of a Cinephiliac Idea? Videographic Film Studies as Material Thinking." Aniki, vol. 1, no. 1, 2014, pp. 49-62.

Keats, Jonathan. Forged: Why Fakes Are the Great Art of Our Age. Oxford UP, 2013.

Kubrick, Stanley, realizador. Barry Lyndon. Peregrine, 1975. 
Lebow, Alisa. "Faking what? Making a Mockery of Documentary." $F$ is for Phony: Fake Documentary and Truth's Undoing, editado por Alexandra Juhasz e Jesse Lerner, U of Minnesota P, 2006, pp. 223-37.

Leitão de Barros, José, realizador. Maria do Mar. Sociedade Universal de Superfilmes, 1930.

Lupo, Rino, realizador. Fátima milagrosa. Lupo Film, 1928.

Mourinha, Jorge. “Com a verdade me enganas.” Ipsilon-Público, 31 julho 2015, pp. 20-21.

Mozos, Manuel, realizador. A glória de fazer cinema em Portugal. Agência da Curta Metragem, 2015.

—. Xavier. Radiotelevisão Portuguesa, 1991-2002.

Nelson, Max. "Redemption." Cinema-Scope, no. 57, 2013. cinemascope.com/spotlight/redemption-miguel-gomes-portugalfrancegermany italy/. Acesso em 22 maio 2017.

Regnier, Isabelle. "Rédemption, élégie européenne à quatre voix par Miguel Gomes." Le Monde, 4 dizembro 2013. www.lemonde.fr/culture/article/ 2013/12/04/redemption-court-metrage-de-miguel-gomes-sur-les-blessuresintimes-de-quatre-chefs-d-etat-europeens_3524065_3246.html. Acesso em 22 maio 2017.

Ribas, Daniel. "Bill Morrison: o arquivo como cinema do futuro." Catálogo curtas Vila do Conde. Curtas CRL, 2013, pp. 94-99.

Sá, Leonor. "O que os 'falsos' têm para os dizer." Wrong Wrong Magazine, vol. 4, 2016. wrongwrong.net/artigo/o-que-os-falsos-tem-para-nos-dizer. Acesso em 22 maio 2017.

Schefer, Raquel. “'Paraíso luso-tropical.' Redemption, de Miguel Gomes.” Atas do IV Encontro Anual da AIM, editado por Daniel Ribas e Manuela Penafria. AIM, 2015, pp. 390-401.

Sousa, António da, realizador. Esplendor selvagem. António de Sousa, 1972.

White, Hayden. Metahistory: The Historical Imagination in NineteenthCentury Europe. Johns Hopkins UP, 1973. 